\title{
Internal model controller based PID with fractional filter design for a nonlinear process
}

\author{
Hemavathy P. R. ${ }^{1}$, Mohamed Shuaib $Y^{2}$, S. K. Lakshmanaprabu ${ }^{3}$ \\ ${ }^{1,3}$ Department of Electronics and Instrumentation Engineering, \\ B.S. Abdur Rahman Crescent Institute of Science and Technology, Chennai, India \\ ${ }^{2}$ Department of Electrical and Electronics Engineering, \\ B.S. Abdur Rahman Crescent Institute of Science and Technology, Chennai, India
}

\begin{tabular}{l}
\hline \hline Article Info \\
\hline Article history: \\
Received Feb 4, 2019 \\
Revised Aug 16, 2019 \\
Accepted Aug 29, 2019 \\
\hline
\end{tabular}

Keywords:

Fractional filter

Hopper tank

IMC based PID

\begin{abstract}
In this paper, an Internal model Controller (IMC) based PID with fractional filter for a first order plus time delay process is proposed. The structure of the controller has two parts, one is integer PID controller part cascaded with fractional filter. The proposed controller has two tuning factors $\lambda$, filter time constant and a, fractional order of the filter. In this work, the two factors are decided in order to obtain low Integral Time Absolute Error (ITAE). The effectiveness of the proposed controller is studied by considering a non linear (hopper tank) process. The experimental set up is fabricated in the laboratory and then data driven model is developed from the experimental data. The non linear process model is linearised using piecewise linearization and two linear regions are obtained. At each operating point, linear first order plus dead time model is obtained and the controller is designed for the same. To show the practical applicability, the proposed controller is implemented for the proposed experimental laboratory prototype.
\end{abstract}

Copyright $(2020$ Institute of Advanced Engineering and Science. All rights reserved.

\section{Corresponding Author:}

Hemavathy P. R.,

Department of Electronics and Instrumentation Engineering,

B. S. Abdur Rahman Crescent Institute of Science and Technology, Chennai, India.

Email: shemavathy@crescent.education

\section{INTRODUCTION}

Most of the process industries like chemical industry, pharmaceutical industry, paper industry have non-linear process tanks namely conical tank, spherical tank and hopper tanks for storage or used in any processing stage. The parameters involved in such cases are flow, level, temperature and pressure, of these one of the major parameter to be considered for control is level in non-linear tanks. The ProportionalIntegral-Derivative control (PID) is the extensively utilized control in process industries. The PID controller involves three parameters i.e. Kp, Ki and Kd. There are many analytical [1, 2], Soft computing techniques [3] and optimization techniques are used by the researchers to design the PID. Model based control was introduced and lead to the development of IMC based PID control [4].

Recently, the fractional calculus appealingly turns out to be progressively well known in scholarly world and industry. It has been gain attention in the field of control theory and other engineering applications. The improvement in the numerical and computational investigation expanded the researcher's eagerness to enhance the controller performance using fractional calculus theory. Eventhough, the integer order controller, especially PI/PID controller dominates the industry, in future the fractional order controller will be widely accepted in the industry, because of its robustness and its flexibility of adjustment in phase and gain characteristics. Nevertheless, many empowering results have been revealed the superiority of the fractional order in model and control applications. 
The development of fractional calculus in the control field lead to design of non-integer PID controller [5-9] and non-integer models [10, 11]. Tuning of fractional controllers for FOPDT systems using analytical methods [12], non-linear systems [13], time delay systems [14, 15], optimization techniques [16-18] are reported in literatures. The Flexibility of FOPID controller is increased by the additional parameters such as fractional order derivative and integrator, but it also increases the complexity of the controller tuning. Many researchers attempted to develop a simplified method for tuning FOPID controller. The IMC based controller strategy provides the additional information of controllers which reduces the tuning efforts. IMC based tuning of FOPID using analytical method attracted few researchers due to its simplified structure [19]. Instead of tuning five parameters in the FOPID controller, the IMC based FOPID controller design procedure reduce the controller tuning parameter into two such as filter time constant and order of filter [20]. Ranganayakulu R et. al (2017) proposed a direct synthesis method for designing IMC based fractional order Controller for the second order system with frequency domain tuning approach [21]. Fractional filter based on IMC is discussed along with the robustness analysis and using optimization technique, the filter and reduction of model for Load frequency control of single area nonreheated thermal power system modeled was done [22].

Tavakoli-Kakhki and M. Haeri in (2010) reported IMC based fractional order PI and PID controller structure. The analytical controller tuning is proposed for the reduced order fractional order model [23]. Pachauri $\mathrm{N}$ et. al proposed modified fractional order IMC based PID controller for nonlinear Bioreactor temperature control application, where the controller tuning parameter such as proportional gain and fractional order filter are tuned using water cycle optimization algorithm [24]. Heydarpoor, S. and Tabatabaei, M., presented the practical applicability of fractional order PI and fractional order IMC based controller for DC motor velocity control application [25]. Bettayeb M, and Mansouri R, a Proposed a IMC based fractional order PID controller for the integer order model. The controller resulted in integer order PID controller with simple fractional filter [26].

Problem Statement: The integer order control like PI and PID is as yet ruled in the industries with consistent control performance. Recently, the fractional calculus based controller got broad attention and interest from the research and industry community due its promising performance. There has been potential literature is available to proving that fractional order controller outperforms than integer order control. However, there is very few tuning methods are presented compared to PI/PID controller. Few researchers attempted Internal Model Controller (IMC) based Fractional order controller where the PI and PID controllers are casted with the fractional order filter. The problem taken for this research work is very clear that the challenges in the designing IMC based controller for time delay process has to be simplified.

Contribution: The main contribution of this paper is that the model based fractional order controller is designed. In this work, a simple IMC based PID with fractional filter is proposed for first order plus dead time process and is employed for the linearized model of non-linear hopper tank process. A simple IMC (Internal model Controller) based PID is proposed for a first order plus time delay process. The proposed controller has two parts, one is integer PID controller part cascaded with fractional filter. The proposed controller has two tuning factors $\lambda$, filter time constant and $\alpha$, fractional order of the filter. The tuning guidelines have been given in straight forward way for the proposed controller. Addition to that, the real time laboratory prototype is developed with hopper tank. This experimental setup will help student community to understand the nonlinear dynamics of real time systems. The proposed controller is implemented in the real time to show the practical applicability.

Highlights:

a. Firstly, the control of hopper tank process is difficult since it is a combination of cylindrical and conical structure. Very few researchers worked in control of hopper tank process.

b. Secondly, though Batteyeb et al designed IMC based PID with fractional filter, the design procedure which we followed is different which resulted in a structure as shown in (17) and good closed loop performance will result if proper control parameters are chosen.

c. The proposed IMC based Fractional order Controller is implemented in the proposed laboratory experimental setup.

\section{PROCESS DESCRIPTION}

The set up consists of a pump, reservoir, process tank (Hopper tank), rotameter, orifice plate, control valve, DPT, air regulator, data acquisition card and personal computer. The setup is shown in Figure 1. The water from the reservoir is discharged through the pump and the process tank viarotameter and control valve. The differential pressure transmitter senses the differential pressure developed across the orifice plate and gives an output current range of $4-20 \mathrm{~mA}$ to the data acquisition system. The personal computer acts as error detector and controller. According to the error signal, corresponding manipulated input signal is given 
to the control valve through current to pressure converter which controlsthe input flow of the liquid to the level system. The detailed technical description of the process set up is given in Table 1. The schematic closed loop experimental setup is shown in Figure 2.

The laboratory setup is interfaced to personnel computer using ADuC841 micro controller based data acquisition (DAQ) card of transmitter is $4-20 \mathrm{~mA}$ current signals, which is converted into 0 to $5 \mathrm{~V}$ range for interfacing with $\mathrm{ADuC} 841$. Data are generated in the single hopper tank by determining open loop response of the system set at manual mode. It is taken from the level process setup by setting the control valve opening as $75 \%$ and $90 \%$. Process variable readings are obtained for each time interval. The input - output characteristics for different operating regions are shown in Figure 3.

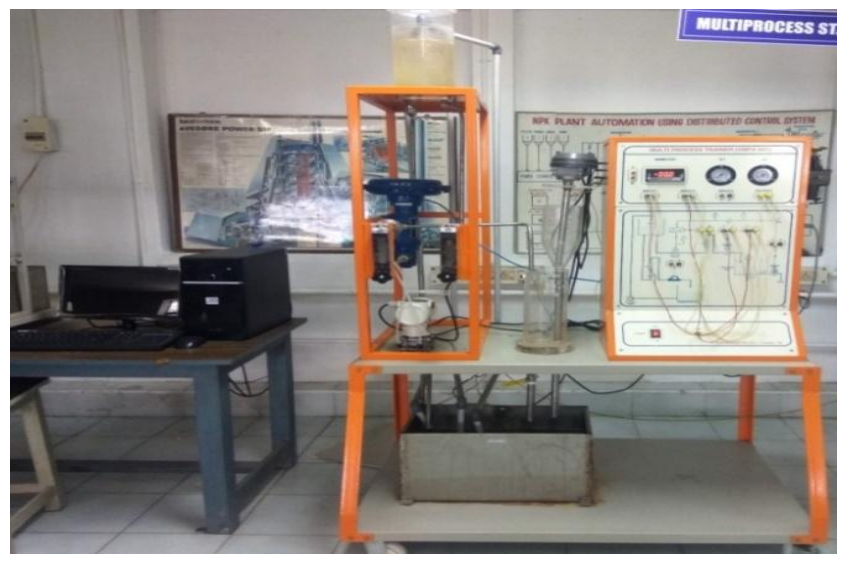

Figure 1. Process setup

Table 1.Technical description

\begin{tabular}{|c|c|}
\hline Component & Specification \\
\hline \multirow[t]{4}{*}{ Differential Pressure Transmitter } & Source - Rose mount. \\
\hline & Built-in sensor $\quad$ - Piezo-electric \\
\hline & Input - $\quad(0-4000) \mathrm{mm} \mathrm{H}_{2} \mathrm{O}$ \\
\hline & $-(4-20) \mathrm{mA}$ at $24 \mathrm{~V}_{\mathrm{dc}} / 2$ wire system \\
\hline \multirow[t]{3}{*}{ Orifice plate } & Upstream distance $-25 \times \mathrm{D}$ \\
\hline & Down stream distance $-5 \times \mathrm{D}$ \\
\hline & Tapping - Flange type. \\
\hline \multirow[t]{2}{*}{ Rotameter } & Range - (10-100) Litre / Hour, Body -Acrylic \\
\hline & End connection $-1 / 4(\mathrm{~F}) \mathrm{BSP}$ \\
\hline \multirow[t]{4}{*}{ Pneumatic Control Valve } & Type - Globe valve \\
\hline & Flow rate - (500/1000) Litre / Hour \\
\hline & Characteristics $\quad-$ Equal $5 \%$ \\
\hline & Valve action - Air to open \\
\hline \multirow[t]{4}{*}{ Level Transmitter } & Type - Dual RF capacitance \\
\hline & Input range $-(0-300) \mathrm{mm}$ \\
\hline & Measuring range $-(0-250) \mathrm{mm}$ \\
\hline & Output - (4-20) $\mathrm{mA}$ at $24 \mathrm{~V}_{\mathrm{dc}} / 2$-wire system \\
\hline \multirow[t]{3}{*}{ Electro-pneumatic converter } & Input pneumatic signal - 20psi constant \\
\hline & Input current signal $-(4-20) \mathrm{mA}$ at $24 \mathrm{~V} \mathrm{DC}$ \\
\hline & Output pneumatic pressure - $(3-15)$ psi \\
\hline \multirow[t]{2}{*}{ Pump } & Voltage - $230 \mathrm{~V}$ AC, $50 \mathrm{~Hz}$ \\
\hline & Discharge - $1200 \mathrm{LPH}$ \\
\hline \multirow[t]{2}{*}{ Process tank } & Body Material -Acrylic \\
\hline & Dimension $-250 \times 120 \mathrm{~mm}$ \\
\hline Reservoir tank & Capacity - 15 liter, Body- MS material \\
\hline \multirow[t]{3}{*}{ Air regulator } & $10.6 \mathrm{Kg} / \mathrm{cm}^{2}$ \\
\hline & $-2.1 \mathrm{Kg} / \mathrm{cm}^{2}$ \\
\hline & Special feature $\quad$ - Air regulator cum filter \\
\hline \multirow[t]{3}{*}{ Flow meter } & Input - (0-100) Liter/hour \\
\hline & Output $\quad-(4-20) \mathrm{mA}$ at $24 \mathrm{~V}_{\mathrm{dc}} / 3$ wire system \\
\hline & Medium - Water \\
\hline
\end{tabular}




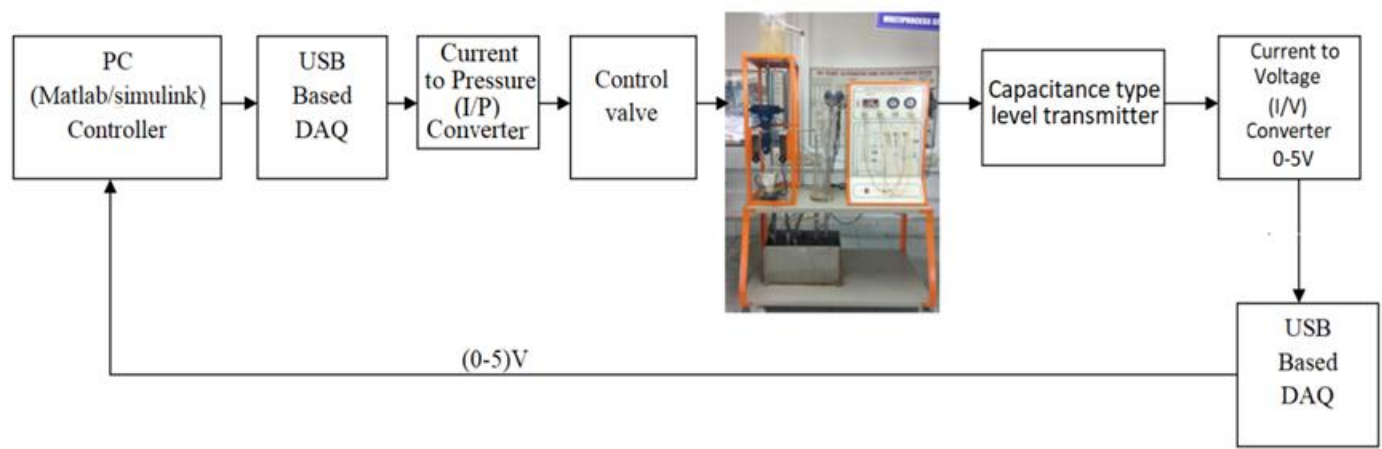

Figure 2. Closed loop experimental setup

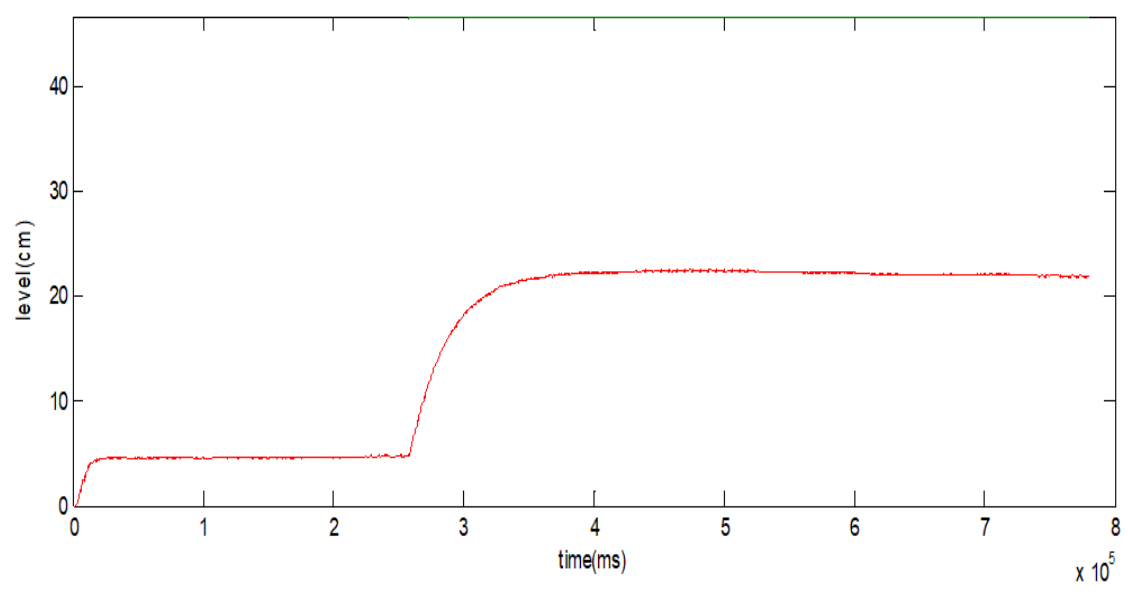

Figure 3. I/O Characteristics

The First Order PlusDead Time (FOPDT) transfer function model for the different operating region is obtained using process reaction curve method. From the Figure 2, the transfer function is obtained around the operating region are given below:

Transfer function for the $1^{\text {st }}$ operating range $(0-10) \mathrm{cm}$ is obtained as (1):

$$
\mathrm{G}_{1}(\mathrm{~s})=\frac{4.556}{92.73 s+1} e^{-30 s}
$$

Transfer function for the $2^{\text {nd }}$ operating range $(10-25) \mathrm{cm}$ is obtained as (2):

$$
\mathrm{G}_{2}(\mathrm{~s})=\frac{17.86}{136 s+1} e^{-13 s}
$$

\section{CONTROLLER DESIGN}

The conventional feedback control system is designed, and controller settings are obtained from analytical expression which is the resultant of IMC method with assumed process models. If the parameters are specified steadily, these two methods produce similar controllers. An advantage of the IMC approach is that, it can reject the disturbances faster than the PID control and it provides a tradeoff among performance and robustness.

The IMC control scheme is illustrated in the Figure 4. The approximated model $\left(G_{m}(s)\right)$ response $y_{m}$, is obtained by applying the manipulated controller output ' $u$ '. The difference between process model $(G(s))$ output $\mathrm{y}$ and approximated model output $\left(\mathrm{y}_{\mathrm{m}}(\mathrm{s})\right)$ is given as a feedback signal to the IMC controller. Mostly, the model output y and approximated model output will not be equal because of the modeling and approximation error, also due to the external disturbance. 


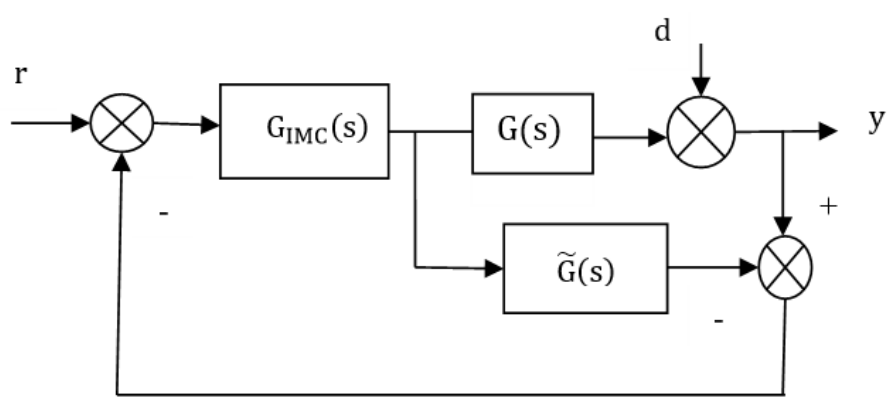

Figure 4. General internal model control structure

The feedback closed loop control system is shown in the Figure 5. The diagrams shown in Figure 4 and Figure 5 are equal if the controller $\mathrm{G}_{\mathrm{c}}(\mathrm{s})$ and $\mathrm{G}_{\mathrm{IMC}}(\mathrm{s})$ satisfies the relation:

$$
\mathrm{G}_{\mathrm{c}}(\mathrm{s})=\frac{\mathrm{G}_{\mathrm{IMC}}(\mathrm{s})}{1-\mathrm{G}_{\mathrm{IMC}}(\mathrm{s}) \widetilde{\mathrm{G}}(\mathrm{s})}
$$

Thus, it can be concluded that any IMC controller, $\mathrm{G}_{\mathrm{IMC}}(\mathrm{s})$ is comparable to a standard feedback controller $\mathrm{G}_{\mathrm{c}}(\mathrm{s})$, and vice versa.

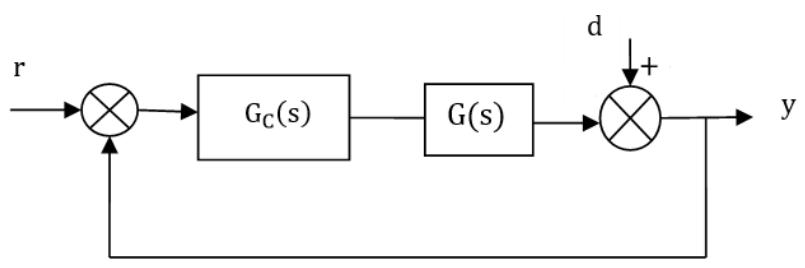

Figure 5.Conventional feedback control

The PID controller $\mathrm{G}_{\mathrm{c}}(\mathrm{s})$ is given as,

$$
G_{c}(s)=k_{p}\left(1+\frac{1}{\tau_{i} s}+\tau_{d} s\right)
$$

Where, $\mathrm{K}_{\mathrm{p}}$ is a Proportional gain, $\tau_{\mathrm{i}}$ is the Integral time constant and $\tau_{\mathrm{d}}$ is the derivative time constant. Proposed IMC - PID Controller with Fractional Filter Design Consider the FOPDT model (5),

$$
G(s)=\widetilde{G}(s)=\frac{\mathrm{ke}^{-\theta s}}{\tau_{\mathrm{p}} \mathrm{s}+1}
$$

where, $\mathrm{k}=$ Process gain, $\tau_{p}=$ Time constant, $\theta=$ dead time The fractional IMC filter (6) considered is

$$
f(s)=\frac{1}{\lambda s^{a}+1}
$$

where, $\lambda=$ filter time constant and $\mathrm{a}=$ fractional order of the filter time constant

$$
\widetilde{G}(s)=\widetilde{G}_{-}(s) \widetilde{G}_{+}(s)
$$

Where, $\widetilde{G}_{-}(s)$ is the invertible part of the model and $\widetilde{G}_{+}(s)$ is the non- invertible part of the model. 


$$
\begin{aligned}
& \widetilde{G}_{-}(s)=\frac{k}{\tau_{p} s+1} \\
& \widetilde{G}_{+}(s)=e^{-\theta s} \\
& G_{I M C}(s)=\frac{f(s)}{\widetilde{G}_{-}(s)}
\end{aligned}
$$

Substitute (6) \& (8), we get

$$
\mathrm{G}_{\mathrm{IMC}}(\mathrm{s})=\frac{1}{\lambda \mathrm{s}^{\mathrm{a}}+1} \frac{\tau_{\mathrm{p}} \mathrm{s}+1}{\mathrm{k}}
$$

The controller $\mathrm{G}_{\mathrm{c}}(\mathrm{s})$ is derived by substituting (11) \& (5) in (3), we get

$$
\begin{aligned}
& \mathrm{e}^{-\theta \mathrm{s}}=\frac{1-0.5 \theta \mathrm{s}}{1+0.5 \theta \mathrm{s}} \\
& G_{c}(s)=\frac{\tau_{p} s+1}{k\left[\left(\lambda s^{a}+1\right)-\frac{1-0.5 \theta s}{1+0.5 \theta s}\right]}
\end{aligned}
$$

Finally, the IMC-PID controller with fractional filter is obtained by substituting (15) in (14), we get

$$
G_{c}(s)=\frac{1}{0.5 \theta \lambda s^{a}+\lambda s^{a-1}+\theta}\left\{\frac{\tau+0.5 \theta}{k}\left[1+\frac{1}{(\tau+0.5 \theta) s}+\left(\frac{0.5 \theta \tau}{\tau+0.5 \theta}\right) s\right]\right\}
$$

Thus the proposed controller has the structure,

$$
G_{c}(s)=H(s)\left[k_{c}\left(1+\frac{1}{\tau_{i} s}+\tau_{d} s\right)\right]
$$

Comparing (18) with (17), we have

Filter transfer function, $\mathrm{H}(\mathrm{s})=\frac{1}{0.5 \theta \lambda s^{a}+\lambda s^{a-1}+\theta}$

$$
\mathrm{K}_{\mathrm{c}}=\frac{\tau+0.5 \theta}{k} ; \tau_{\mathrm{i}}=\tau+0.5 \theta ; \tau_{d}=\frac{0.5 \theta \tau}{\tau+0.5 \theta}
$$

Using the same procedure as above, IMC based PID controller with integer filter (i.e.f(s) $=\frac{1}{\lambda s+1}$ ) is obtained as given in (19),

$$
G_{c}(s)=\frac{1}{\left(\frac{0.5 \theta \lambda}{\lambda+\theta}\right) s+1}\left\{\frac{(0.5 \theta+\tau)}{k(\lambda+\theta)}\left[1+\frac{1}{(0.5 \theta+\tau) s}+\frac{0.5 \theta \tau s}{(0.5 \theta+\tau)}\right]\right\}
$$

Where, Filter transfer function, $\mathrm{H}(\mathrm{s})=\frac{1}{\left(\frac{0.5 \theta \lambda}{\lambda+\theta}\right) s+1} ; \mathrm{K}_{\mathrm{c}}=\frac{(0.5 \theta+\tau)}{k(\lambda+\theta)} ; \tau_{\mathrm{i}}=\tau+0.5 \theta ; \tau_{d}=\frac{0.5 \theta \tau}{\tau+0.5 \theta}$

\section{RESULTS AND ANALYSIS}

\subsection{Simulation study}

The IMC based PID controller and IMC based PID with fractional filter (Proposed method) is designed for the two linear regions of the hopper tank process. The proposed method is compared with Bettayeb et al [26]. The controller settings for region 1 obtained using the (19), Bettayeb et al method and by (17) respectively are tabulated in Table 2. 
For region 1: The transfer function for region 1 is given by $\mathrm{G}_{1}(\mathrm{~s})$,

$$
\mathrm{G}_{1}(\mathrm{~s})=\frac{4.556}{92.73 s+1} e^{-30 s}
$$

Table 2. Controller settings for region 1

\begin{tabular}{lccccc}
\hline \multicolumn{1}{c}{ Controller } & $\mathrm{k}_{\mathrm{p}}$ & $\mathrm{k}_{\mathrm{i}}$ & $\mathrm{k}_{\mathrm{d}}$ & Filter transfer function \\
\hline IMC based PID & 0.706 & 107.73 & 12.91 & $\frac{1}{1+18.5 s}$ \\
IMC based PID with fractional filter (Bettayeb et al) [26] & 1.576 & 107.73 & 12.91 & $\frac{1}{1+1.76 s^{0.11}}$ \\
IMC based PID with fractional filter (Proposed method) & 23.65 & 107.73 & 12.91 & $\frac{1}{228 s^{1.02}+15.2 s^{0.02}+30}$ \\
\hline
\end{tabular}

The filter transfer function for the IMC based PID with fractional filter (Bettayeb et al) is designed by choosing $\alpha=0.11$ and $\tau_{c}=1.76$ (where, $\omega_{\mathrm{c}}=0.028$ ). For the proposed method, the $\lambda$ value is chosen to be 15.2 and a as 1.02 respectively. The closed loop step response of the process for the $1^{\text {st }}$ operating range is shown in Figure 6. The set value is given to be $5 \mathrm{~cm}$ and it is observed that the proposed controller has minimum overshoot and settling time. Figure $7 \&$ Figure 8 shows the closed loop response of the process for variations in time constant and gain respectively in order to analyse the controller robustness.

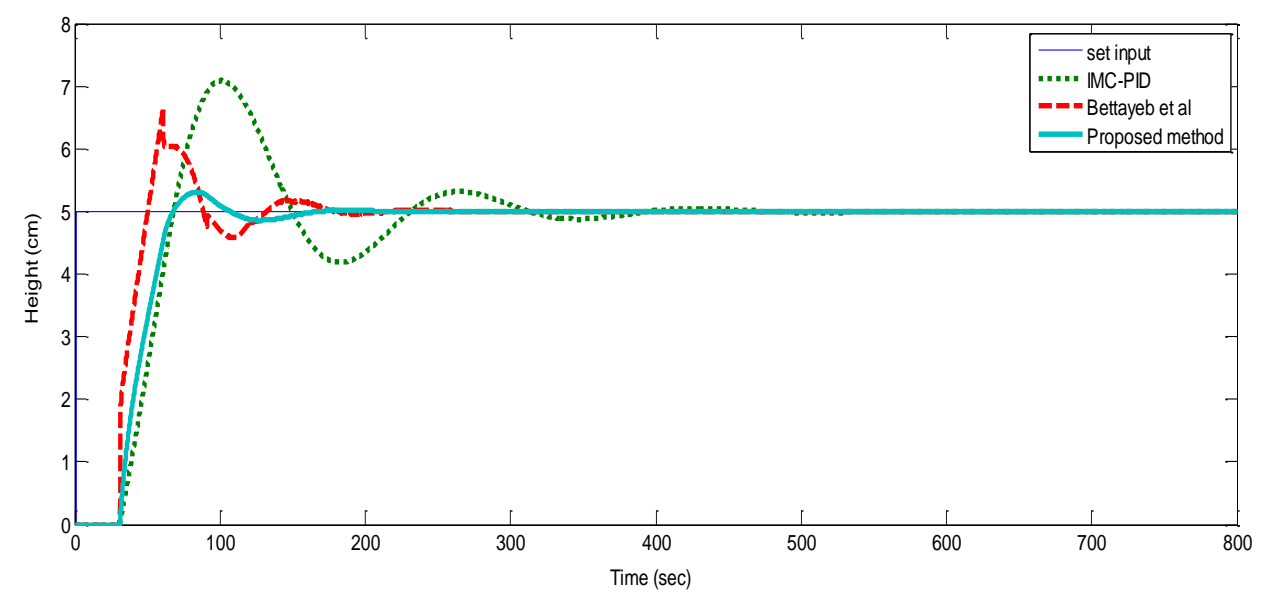

Figure 6. Closed loop step response for region 1

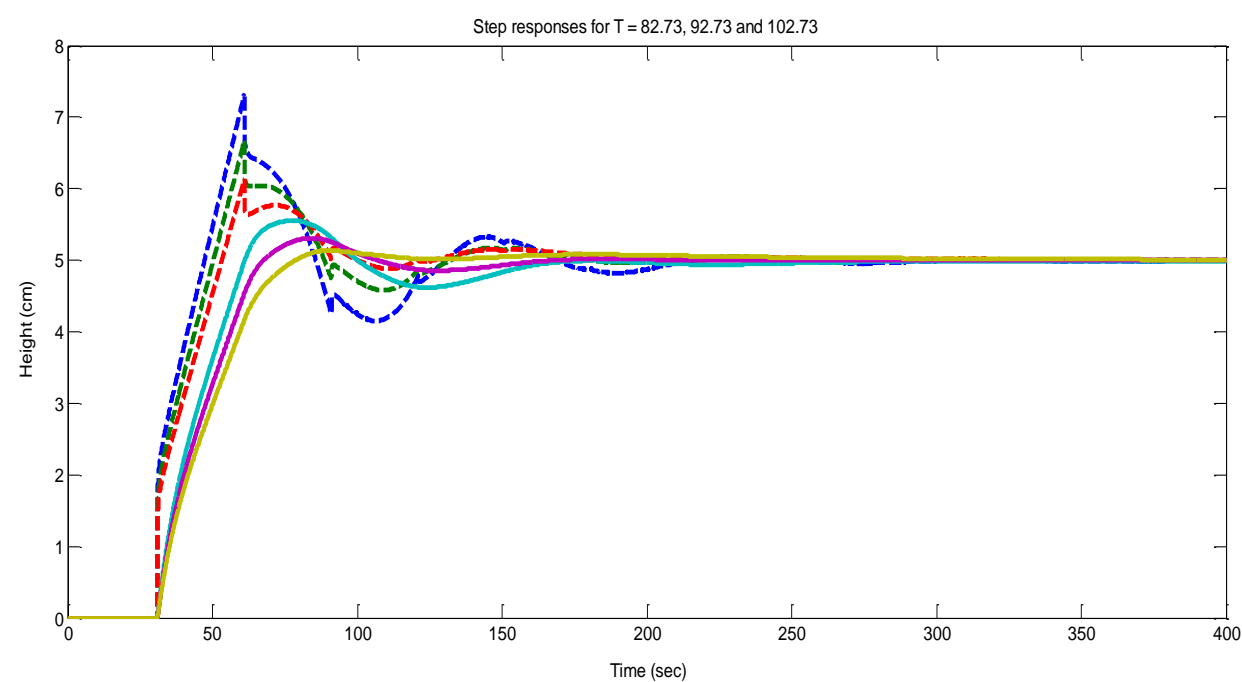

Figure 7. Closed loop response with variations in time constant, T 


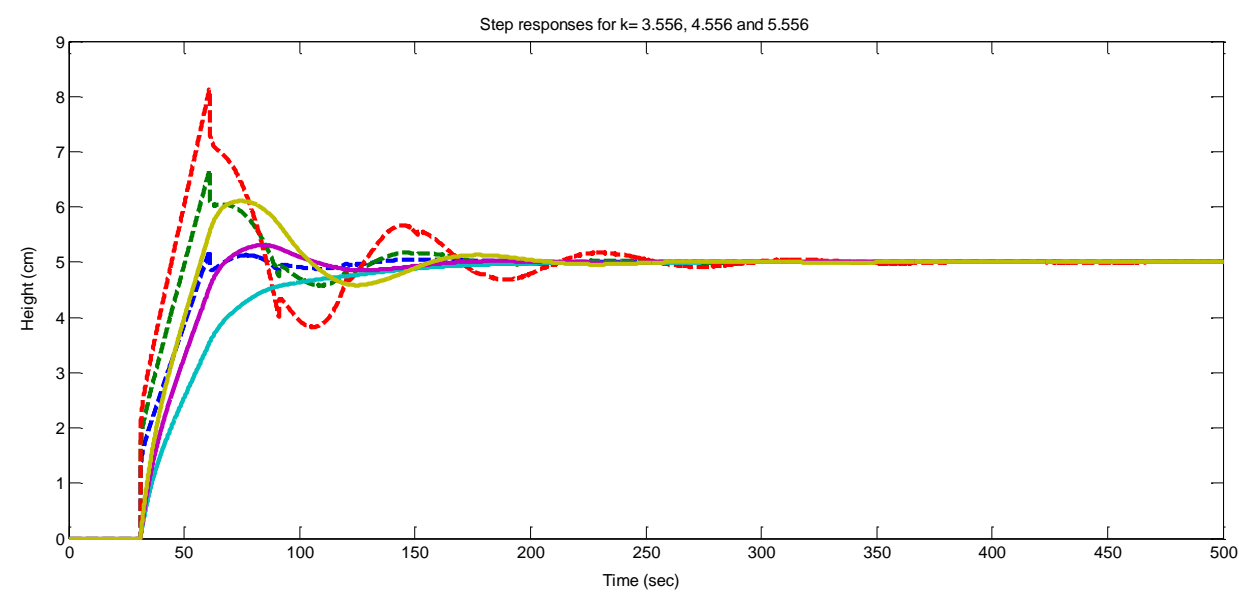

Figure 8. Closed loop response with variations in gain, $\mathrm{K}$

The setpoint tracking performance of the proposed controller for region 1 is verified by changing the set values and its response is shown in Figure 9. The proposed controller can able to track the set point changes efficiently than the other controllers.

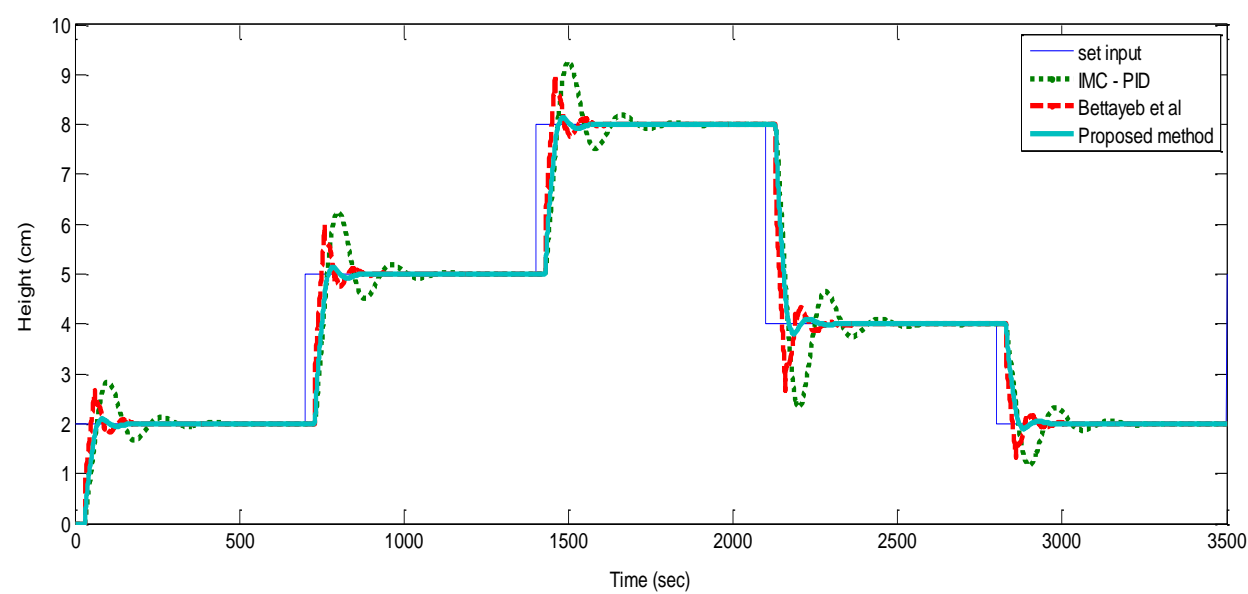

Figure 9. Closed loop response for region 1 with set point tracking

For region 2: The transfer function for region 2,

$$
\mathrm{G}_{2}(\mathrm{~s})=\frac{17.86}{136 s+1} e^{-13 s}
$$

The controller settings found for region 2 using the (19), Bettayeb et al method and by (17) are tabulated in Table 3.

Table 3. Controller settings for region 2

\begin{tabular}{lcccc}
\hline \multicolumn{1}{c}{ Controller } & $\mathrm{K}_{\mathrm{p}}$ & $\tau_{\mathrm{i}}$ & $\tau_{\mathrm{d}}$ & Filter transfer function \\
\hline IMC based PID & 0.532 & 142.5 & 6.203 & $\frac{1}{1+8.5 s}$ \\
IMC based PID with fractional filter(Bettayeb et $\mathrm{al}$ ) [26] & 1.23 & 142.5 & 6.203 & $\frac{1}{1+2.05 s^{0.11}}$ \\
IMC based PID with fractional filter(Proposed method) & 7.97 & 142.5 & 6.203 & $\frac{1}{42.25 s^{1.02}+6.5 s^{0.02}+13}$ \\
\hline
\end{tabular}


The filter transfer function for the IMC based PID with fractional filter is designed by choosing $\alpha=0.11$ and $\tau_{c}=2.05$ (where, $\omega_{c}=0.052$ ). For the proposed method, the $\lambda$ value is chosen to be 6.5 and a as 1.02 respectively. The setpoint tracking behaviour of the designed controller is shown in Figure 10 and it is evident that the proposed method has the ability to adapt to set point changes faster than the other methods.

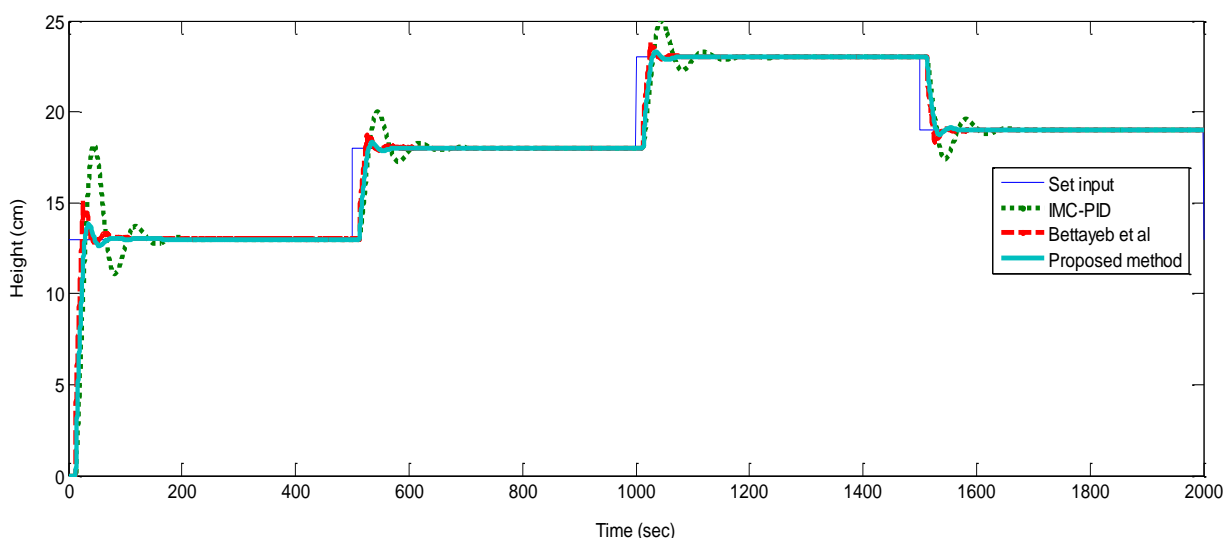

Figure 10. Closed loop step response for region 2 with set point tracking

\subsection{Real time implementation of the proposed controller}

Using the concept of fractional calculus, a toolbox has been developed by AlekseiTepliakov named as FOMCON [27]. The tool is developed for designing fractional model and controller. Fractional integrator, fractional differentiator, fractional order transfer function and fractional PID controller are available as simulink block set in FOMCON toolbox. The real time interfacing between the transmitter (capacitive type level transmitter) \& controller (Personal computer) is done using the DAQ card. The DAQ card and Matlab are operated in same windows/2000/XP platform.

Figure 11 shows the real time implementation of PID controller with fractional filter using Matlab/simulink. The "Query instrument block" is used to acquire input from the level transmitter as digital bit of data in which the sampling time and interacting information are selected with its block itself. The controller output is sent to the DAQ card through the "To instrument block". The output from DAQ card is used to actuate the final control element (Control valve). The real time implementation of proposed controller with Matlab/ Simulink real time query instrument tool box. The real time implementation of proposed controller is shown in the Figure 12.

The time domain performance indices are calculated for the IMC based PID with integer filter and for fractional filter (Bettayeb et al and proposed method) and tabulated in Table 4. It is observed from the tabulated results in Table 4 is that, the IMC based PID controller with fractional filter has less overshoot and fast settling time compared with the other.

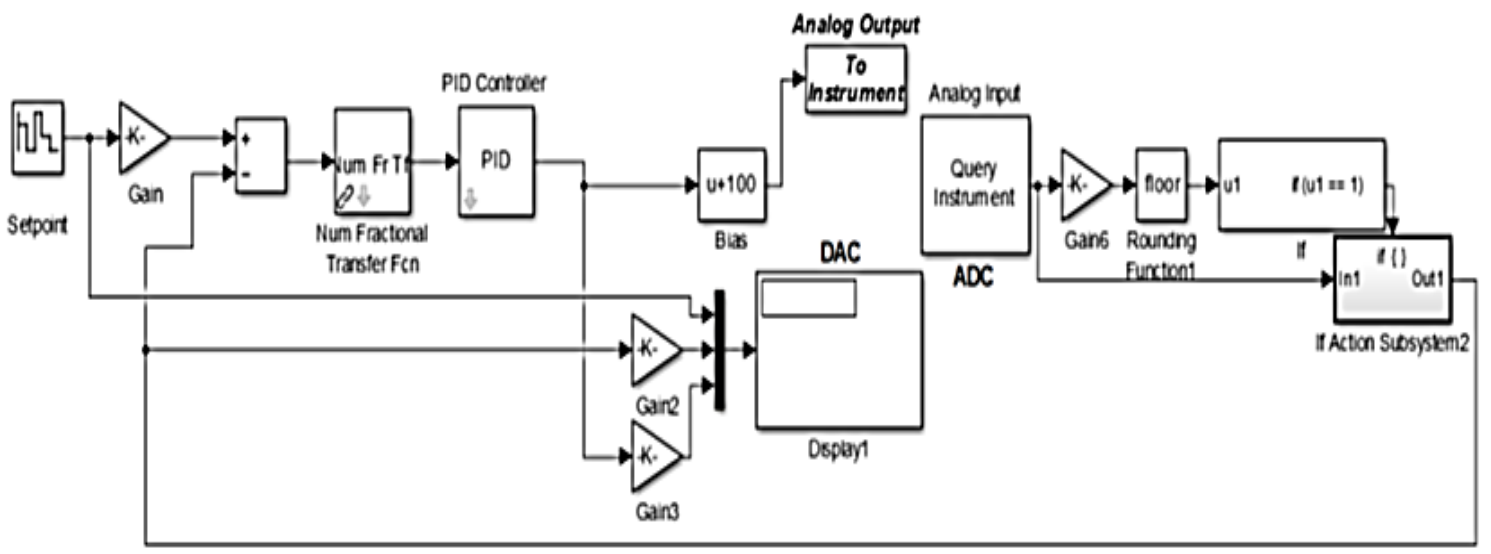

Figure 11. Real time implementation of PID controller with fractional filter using Matlab/Simulink 


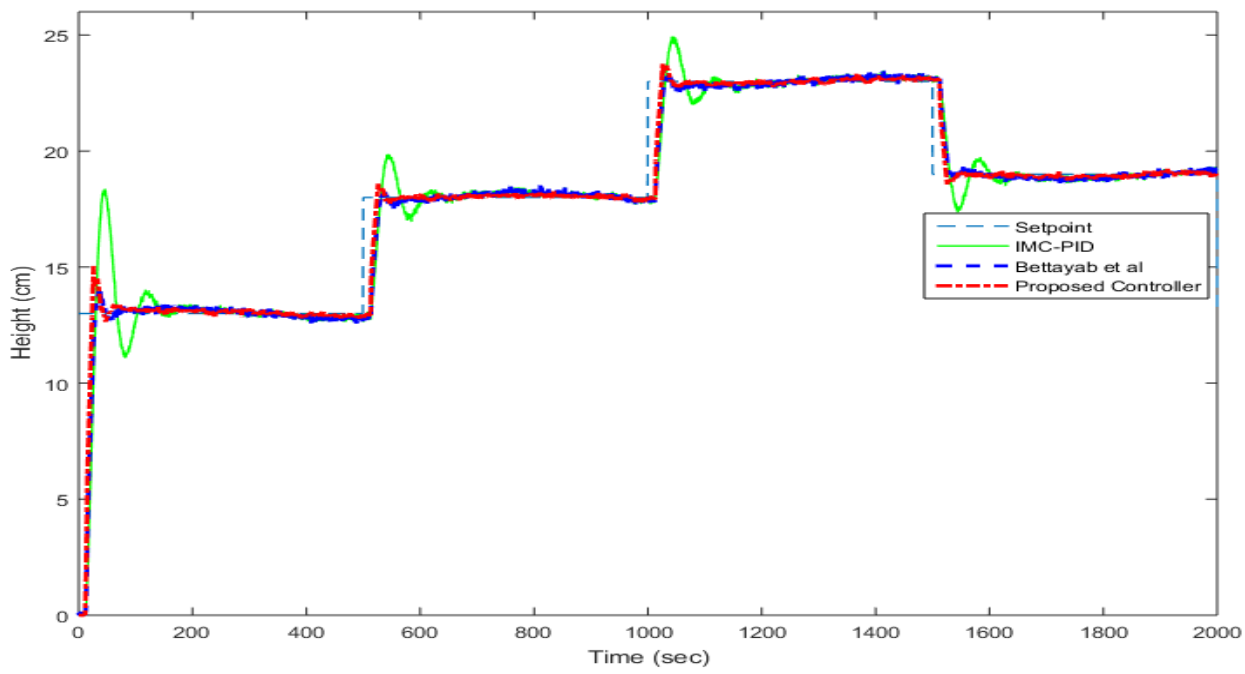

Figure 12. Real time implementation of proposed controller.

Table 4. Time domain performance indices

\begin{tabular}{|c|c|c|c|c|c|c|c|c|c|c|}
\hline \multirow[b]{2}{*}{ Controller } & \multicolumn{6}{|c|}{ Region 1} & \multicolumn{4}{|c|}{ Region 2} \\
\hline & $\mathrm{PO}$ & $\begin{array}{l}\text { Settling } \\
\text { time, (ts) }\end{array}$ & ITAE & ISE & ITAE $_{\mathrm{sp}}$ & $\mathrm{PO}$ & $\begin{array}{l}\text { Settling } \\
\text { time, (ts) }\end{array}$ & ITAE & ISE & ITAE $_{\mathrm{sp}}$ \\
\hline IMC based PID & 7.09 & 634.5 & $3.386 \times 10^{4}$ & 1272 & $1.79 \times 10^{6}$ & 19.5 & 250.3 & $1.79 \times 10^{4}$ & 4349 & $5.225 \times 10^{5}$ \\
\hline $\begin{array}{l}\text { IMC based PID with } \\
\text { fractional filter } \\
\text { (Bettayeb et al) [19] }\end{array}$ & 6.65 & 305.7 & 7982 & 845.3 & $9.45 \times 10^{5}$ & 15.72 & 240.2 & 4018 & 2886 & $2.87 \times 10^{5}$ \\
\hline $\begin{array}{l}\text { IMC based PID with } \\
\text { fractional filter } \\
\text { (Proposed method) }\end{array}$ & 5.3 & 216.7 & 6883 & 960.9 & $9.20 \times 10^{5}$ & 14.82 & 138.8 & 3846 & 3279 & $2.68 \times 10^{5}$ \\
\hline
\end{tabular}

\section{CONCLUSION}

A simple IMC based PID controller with fractional filter for a FOPDT process is proposed. The proposed design is applied to the non-linear hopper tank process modeled linearized as FOPDT process. The simulation result shows the effectiveness of the designed controller. The performance indices of the proposed controllerare compared with IMC based PID with fractional filter (Bettayeb et al) and IMC based PID and results are tabulated. From the tabulation, it is clear that the proposed controller has minimum overshoot, settling time and improved robustness. The proposed controller is implemented practically with the laboratory hopper tank prototype inorder to control the level of the tank.

\section{REFERENCES}

[1] Astrom K.J, T. Hagglund, "PID controllers Theory, Design and Tuning," $2^{\text {nd }}$ edition, Instrument Society of America, 1994.

[2] J. G. Ziegler and N. B Nichols, “Optimum Settings for Automatic Controller,"J.Dyn.Sys. Meas., Control, 115(2B), 220-222, June 1993.

[3] Dineva, A., Mosavi, A., Ardabili, S.F., Vajda, I., Shamshirband, S., Rabczuk, T. and Chau, K.W, "Review of soft computing models in design and control of rotating electrical machines," Energies, 12(6), p.1049, 2019.

[4] Pistikopoulos, Efstratios N., Nikolaos A. Diangelakis, Richard Oberdieck, Maria M. Papathanasiou, IoanaNascu, and Muxin Sun. "PAROC-An integrated framework and software platform for the optimisation and advanced model-based control of process systems," Chemical Engineering Science, 136, pp. 115-138, 2015.

[5] Poblubny I, "Fractional-order system and $\mathrm{PI}^{\lambda} \mathrm{D}^{\mu}$ controllers," IEEE TransAutom Control, 44(1):208-14, Jan 1999.

[6] Concepcion A. Monje, Blas M. Vinagre , Vicente Feliu, YangQuan Chen, "Tuning and auto-tuning of fractional order controllers for industry applications," Control Engineering Practice, 16, 798-812, (2008).

[7] Shah, P. and Agashe, S, "Review of fractional PID controller," Mechatronics, 38, pp.29-41, 2016.

[8] R. Ranganayakulu, G. UdayBhaskarBabu, A. Seshagiri Rao, DipeshShikchandPatle, "A comparative study of fractional order $\mathrm{PI}^{\lambda} / \mathrm{PI}^{\lambda} \mathrm{D}^{\mu}$ tuning rules for stable first order plus time delay processes," Resource-Efficient Technologies, 2, S136-S152, (2016). 
[9] Reyad El-Khazal, "Fractional-order $\mathrm{PI}^{\lambda} \mathrm{D}^{\mu}$ controller design," Computers \& Mathematics with Applications, Volume 66, Issue 5, Pages 639-646, 2013.

[10] Tavakoli-Kakhki, Mahsan, Mohammad Haeri, and Mohammad Saleh Tavazoei, "Simple fractional order model structures and their applications in control system design," European Journal of Control, Vol. 16, no. 6, pp. 680-694, 2010.

[11] M. Al-Dhaifallah, N. Kanagaraj, and K. S. Nisar, "Fuzzy Fractional-Order PID Controller for Fractional Model of Pneumatic Pressure System,” Mathematical Problems in Engineering, Article ID 5478781, 9 pages, 2018.

[12] RoohallahAzarmi, MahsanTavakoli-Kakhki, Ali Khaki Sedigh, AlirezaFatehi, "Analytical design of fractional order PID controllers based on the fractional set-point weighted structure: Case study in twin rotor helicopter," Mechatronics, Volume 31, Pages 222-233, 2015.

[13] NoureddineBouarroudj, DjamelBoukhetala, and Fares Boudjema, "Sliding-Mode Controller Based on Fractional Order Calculus for a Class of Nonlinear Systems," International Journal of Electrical and Computer Engineering (IJECE), Vol. 6, No. 5, pp. 2239 - 2250, October 2016.

[14] P.R.Hemavathy, Y. Mohamed Shuaib and S. K. Lakshmanaprabu, "Design of Smith Predictor Based Fractional Controller for Higher Order Time Delay Process," Computer Modeling in Engineering Sciences, vol.119, no.3, pp.481-498, 2019.

[15] Feliu-Batlle V, Rivas-Perez, R. and Castillo-García, F., "Simple fractional order controller combined with a Smith predictor for temperature control in a steel slab reheating furnace," International Journal of Control, Automation and Systems, Volume 11, Issue 3, pp 533-544, 2013.

[16] N. Ramesh Raju, P. Linga Reddy, "Robustness Study of Fractional Order PID Controller Optimized by Particle Swarm Optimization in AVR System," International Journal of Electrical and Computer Engineering (IJECE), Vol. 6, No. 5, pp. 2033-2040, October 2016.

[17] Ramezanian, H., Balochian, S. and Zare, A, "Design of Optimal Fractional-Order PID Controllers Using Particle Swarm Optimization Algorithm for Automatic Voltage Regulator (AVR) System," Journal of Control, Automation and Electrical Systems, Volume 24, Issue 5, pp 601-611, 2013.

[18] Indranil Pan, Saptarshi Das, "Frequency domain design of fractional order PID controller for AVR system using chaotic multi-objective optimization," International Journal of Electrical Power \& Energy Systems, Volume 51, Pages 106-118, 2013.

[19] Dazi Li, Lang Liu, QibingJin, Kotaro Hirasawa, "Maximum sensitivity based fractional IMC-PID controller design for non-integer order system with time delay," Journal of Process Control, 31, pp.17-29, July 2015.

[20] Lakshmanaprabu, S. K., U. SaburaBanu, and P. R. Hemavathy, "Fractional order IMC based PID controller design using Novel Bat optimization algorithm for TITO Process," Energy Procedia, 117, pp.1125-1133, June 2017.

[21] R. Ranganayakulu, G. UdayBhaskarBabu and A. Seshagiri Rao, "Fractional filter IMC-PID controller design for second order plus time delay processes," Cogent Engineering, 4: 1366888, 2017.

[22] KasireddyIdamakanti, Abdul Wahid Nasir, and Arun Kumar Singh, "Non-integer IMC based PID Design for Load Frequency Control of Power System through Reduced Model Order," International Journal of Electrical and Computer Engineering, 8.2, 837, 2018.

[23] Tavakoli-Kakhki, Mahsan, and Mohammad Haeri, "Fractional order model reduction approach based on retention of the dominant dynamics: Application in IMC based tuning of FOPI and FOPID controllers," ISA transactions 50, no. 3, pp. 432-442, 2011.

[24] Pachauri, Nikhil, Asha Rani, and Vijander Singh. "Bioreactor temperature control using modified fractional order IMC-PID for ethanol production," chemical engineering research and design, 122 pp. 97-112, 2017.

[25] Heydarpoor, S. and Tabatabaei, M., "Velocity control of a DC motor based on fractional order PI and IMC-based fractional order controllers," International Journal of Advanced Mechatronic Systems, 7(1), pp.35-45, 2016.

[26] Bettayeb M, and Mansouri R. "IMC-PID-fractional-order-filter controllers design for integer order systems" ISA transactions 53, no. 5: 1620-1628, (2014).

[27] TepljakovAleksei, Eduard Petlenkov, and JuriBelikov, "FOMCON: Fractional-order modeling and control toolbox for MATLAB," In Proceedings of the 18th International Conference Mixed Design of Integrated Circuits and Systems-MIXDES 2011, pp. 684-689. IEEE, 2011.

\section{BIOGRAPHIES OF AUTHORS}

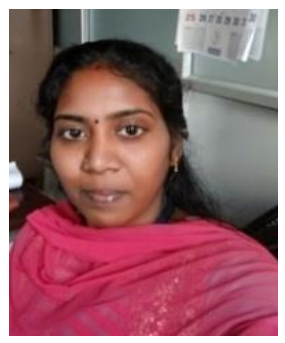

P. R. Hemavathy completed her BE degree in Instrumentation and control Engineering from Madras University, Chennai, India, in 2003. She received her Post Graduate degree in Control and Instrumentation Engineering in the year 2007 from Anna University, Chennai. She is currently working as assistant professor in the department of Electronics and Instrumentation and pursuing her PhD degree in design of fractional controllers in the Department of Electronics and Instrumentation. Her area of interest includes intelligent control, fractional order control, model based control and Industrial automation. 


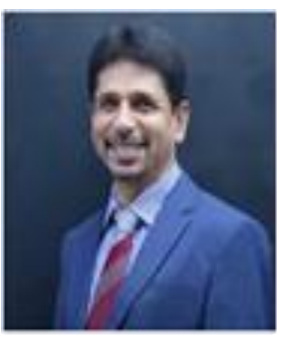

Y. Mohamed Shuiab completed his bachelor's degree in Electrical and Electronics Engineering in the year 1994 from Madras University, Chennai. He received his M.E. degree in Power system engineering in the year 2002 from Annamalai University. He has been awarded his doctoral degree from JNT University, Hyderabad in power system engineering in the year 2015.

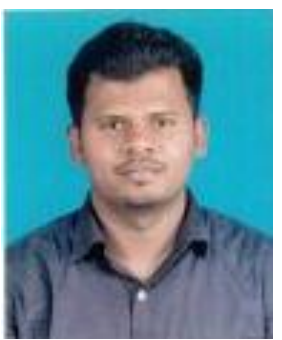

S. K. Lakshmanaprabu received his BE degree in Electronics and Instrumentation Engineering from Anna University, Chennai, India, in 2009. He completed his Post Graduate degree in Industrial Engineering in the year 2011 from Anna University, Trichy. He is currently pursuing his $\mathrm{PhD}$ degree in Multivariable Optimal Control in the Department of Electronics and Instrumentation. He is currently working as senior research fellow in B.S. Abdur Rahman Crescent Institute of Science and Technology, Chennai, India. 